\title{
EL PAISAJE, LA GUERRA Y EL NACIONALISMO MARROQUí EN LAS CRÓNICAS DE JOSÉ MARÍA SEVILLANO (1925-1926)
}

\author{
Dra. D. ${ }^{a} M .{ }^{a}$ Josefa Parejo Delgado \\ I.E.S. "Vicente Aleixandre". Sevilla. España
}

"La obra tan brillantemente realizada,durará dos, tres, cinco generaciones, pero, al cabo, el pueblo musulmán reclamará su libertad (por eso), el pueblo español desconfia... de lo que puede venir mañana..Marruecos se encuentra civilizado y nuestra misión ha concluido".Menipo, 1927.

\section{INTRODUCCIÓN}

Año trascendental en el Protectorado hispanofrancés sobre Marruecos fue 1925. Ese año, comienza con la extensión de la acción de Abd el Krim al Yebala, ocupando Xauen y atacando al Raisuni en Tazarut. La reorganización de la Legión, mas tarde, el Tercio, será el comienzo de la contraofensiva española.La ocupación de Alcazarseguer en marzo, y la presión en la zona de Melilla sobre Tizi Azza no impiden que Abd el Krim ataque la línea francesa del Uarga. Este revés, hizo pensar al país galo en la necesidad de una operación conjunta que fue discutida en junio-julio de ese año en Madrid. La vigilancia marítima, Tánger, la colaboración militar y los limites de la zona de influencia fueron algunos de los temas tratados en la Conferencia.El 25 de julio es nombrado Jalifa, Muley el Hassan Ben el Medhi Ben Ismail.La muerte de Raisuni desvió el objetivo hacia la cabila de Abd el Krim, que días antes de la operación de Alhucemas ataca Cudia Tahar frente a Tetúan en un intento de contener la llegada de efectivos franco-españoles;dicha población fue liberada por las tropas españolas el día 13, y a partir de ese día cayeron Morro Viejo, Buyibar, Rocosa y Axdir, residencia del rebelde.Los éxitos en las operaciones militares llevan a nuevos nombramientos en ambos Protectorados Mr.Steeg en la zona francesa. Castro Girona, Berenguer y Sanjurjo como Alto Comisario en la española.

El Convenio de Cooperación firmado por España y Francia en febrero de 1926 permite la sumisión de Anyera, y del Jeriro, que desde hacia tiempo hostigaba Tetuán. El 13 de julio de ese año se firma un nuevo acuerdo franco-español en París. El Comandante Capaz efectúa un raid por Gomara.En la zona de Larache, las tropas españolas recuperan Xauen, al frente del general Sanjurjo. La utilización de columnas fuertes y móviles, el empleo de harkas y mehallas y el desarme total del pais que queda en la retaguardia fue- 
ron las claves del éxito militar. Las operaciones militares de 1927 aseguraron la ocupación de Bab Taza y la reducción del Tensamani.Quedando finalizado el desarme en 1930.'

El grupo de artículos agrupados bajo el epígrafe de Consideraciones o sus reseñas de las operaciones militares en el de El Noticiero en Marruecos son una contribución literaria de gran calidad que se unen al ya larga serie de literatura sobre Marruecos planteada en obras como El Blocao de José Díaz Fernández, la novela antibelicista de Ramón J.Sender Imán (1930) y las obras de los militares Franco Diario de una bandera, Mola Dar Akabba, Kindelán, Ejército y Política, y Vigón, Teoría del militarismo. El autor fírma los artículos usando dos seudónimos según se trate de crónicas de campaña o de análisis crítico de la situación. El cronista es José Maria Sevillano y el crítico Menipo.

\section{EL PAISAJE}

En las crónicas de las operaciones militares José María Sevillano no sólo plantea las interrogantes que suscita la estrategia antigua y nueva para resolver la guerra sino que se detiene en el espacio donde se desarrollan los acontecimientos. La ciudad y el campo son analizados por él con una óptica donde se mezclan lo literario, lo artístico y lo militar. El campo marroquí, sus colores el azul del cielo y el amarillo de sus campos de trigo, suscitan en su espiritu, opiniones encontradas. Hay en su obra una especial sensibilidad por la destrucción del campo y de la ciudad debido a la guerra. Lamenta la tala de los árboles y la rapiña de los frutos de los árboles asentados en barrancos y bosques. Su efecto es sólo comparable al de la tala y el fuego.El campo entre Tánger y Tetúan es un espacio humanizado con aduares, repletos de familias, que aprovechan los olivos, las higueras, las adelfas y la caza que existen en sus alrededores. Es una zona abrupta y dificil, donde se mezclan bellas cascadas, desfiladeros, montes, y valles con posiciones y blocaos vigilados por ocho o diez soldados con alambradas. Un espacio propicio a la emboscada e inaccesible al tránsito de coches y animales. Un paisaje encerrado en una orgia colorista de azules, amarillos, verdes y blancos como si se tratara una pintura impresionista.

En la zona rifeña admira la fertilidad del suelo como expone al describir sus verdes campos de sembradura y los grandes rebaños, que se alimentan de los suculentos pastos. Su sol es jocundo y primaveral sin manchas. Un espacio donde se alternan tierras incultas que demandan brazos y maquinaria, con barrancos encrespados, en medio de valles, que como el de Guis nos deleita con sus almendros, higueras, cebada y granadas. Claves para su mejora podían ser la explotación de las minas de Yebel Hamman y el ferrocarril. Sus observaciones personales se ven enriquecidas por las contenidas en los viajes de Bey el Abassi;

1 GARCIA FIGUERAS T. Marruecos. Barcelona, Ed, Fe, 1939.

PAREJO DELGADO M.J."Las Impresiones Marruecas de Menipo como fuente de información histórica"(1920-24).II Congreso Internacional del Estrecho de Gibraltar. Madrid, 1995, p.157-180. 
coincidiendo ambos en la necesidad de campesinos y pastores que permitan un mejor aprovechamiento del suelo. ${ }^{2}$

Xauen, Tánger y Tetúan, son las tres ciudades con mayor número de referencias en sus escritos. En Xauen, (Aracena de Marruecos) nos deleita con su muralla con el Kola y el Mago, la Alcazaba, la Mezquita y la belleza de la cuenca del bajo Lau y por último su mestiza gastronomía que combina los pinchitos, la torta moruna y el pescaito frito. Tánger es el cosmopolitismo. La ciudad comercial y de servicios al estilo de las grandes urbes europeas donde los cafes, el juego, y los zocos ocultan las conspiraciones y aviesos intereses de la política europea.Tetúan con sus reslos arqueológicos romanos es el eje de la vega húmeda de Río Martín.Menipo compara su crecimiento urbano con el de Sevilla explicando como los nuevos barrios marginales como Villalatas no han surgido fruto de la industria sino de la falta de ocupaciones agrícolas. Denuncia la incultura, la inmoralidad y la falta de salubridad de las nuevas viviendas pero elogia el mestizaje cultural como punto de partida para una mejor gestión del Protectorado.

Ketama es para José María Sevillano la otra cara de Marruecos. Es la zona más parecida a la Europa alpina donde nieva en abril y las altas cotas alternan con llanuras y bosques de pinos.Los vientos y la nieve ocasionan grandes destrozos entre la población y el campo. ${ }^{3}$

\section{LAS OPERACIONES MILITARES}

En una serie de artículos, agrupados bajo el denominador común de "Consideraciones" o "El Noticiero en Marruecos",y firmados con los seudónimos de José Maria Sevillano o Menipo, el militar José Delgado, analiza como testigo de primera fila el desarrollo de las operaciones militares en Marruecos, que culminarán en estos años con el desembarco de Alhucemas y la reconquista de la zona occidental.

Durante el primer año, el cronista está destinado desde agosto en el Regimiento de Infantería Granada 34, en octubre al Batallón de Cazadores de Estella $\mathrm{n}^{\circ} 14$ con sede en Fondak Ain Yedida y en diciembre, al de Cazadores de Africa $\mathrm{n}^{\circ} 6$ con sede en Izarduy.En sus artículos La lección del Islam y Luego vendrá la Historia reflexiona sobre la campaña de Septiembre y el éxito militar que supuso la operación conjunta franco-española en Alhucemas.La dureza de la resistencia rifeña demuestra a Europa y a España, que el nacionalismo marroquí no es algo pasajero sino que encubre una fuerte tenacidad como lo avala la calidad y cantidad de las revueltas contra la civilización.Del mismo modo llega a la conclusión de que la lucha no se aviva por el desconocimiento de la civilización europea,

2 SEVILLANO J.M."El Naticiero en Marruecos".Croquis de Beni Aros.El Noticiero Sevillano 24-XI-1926.Los cereales son de excelente calidad, especialmente el trigo y la cebada.Entre las frutas sobresalen las naranjas y ciruelas de Tetúan y Larache.

3 SEVILLANO J.M."El Noticiero en Maruecos."Los efectos del desarne".El Noticiero Sevillano.Sevilla 24-41927;La invasión y el castigo de Sumata".El Noticiero Sevillano,21-5-1926;"De Tetúan a Melilla en burro I".El Noticiero Sevillano,6-10-1926;"De la campaña de Africa.Estado actual del problema",25-5-1926;"El Noticiero en Marruecos.De Bencarrich a Xauen",18-8-1926;'Tánger para España?,31-8-1926;MENIPO,"Narraciones blancas. Una partida de Caza".El Noticiero Sevillano, 1925;"Consideraciones Villalatas", 20-11-1926;"El afán de los ases,25-11-1926. 


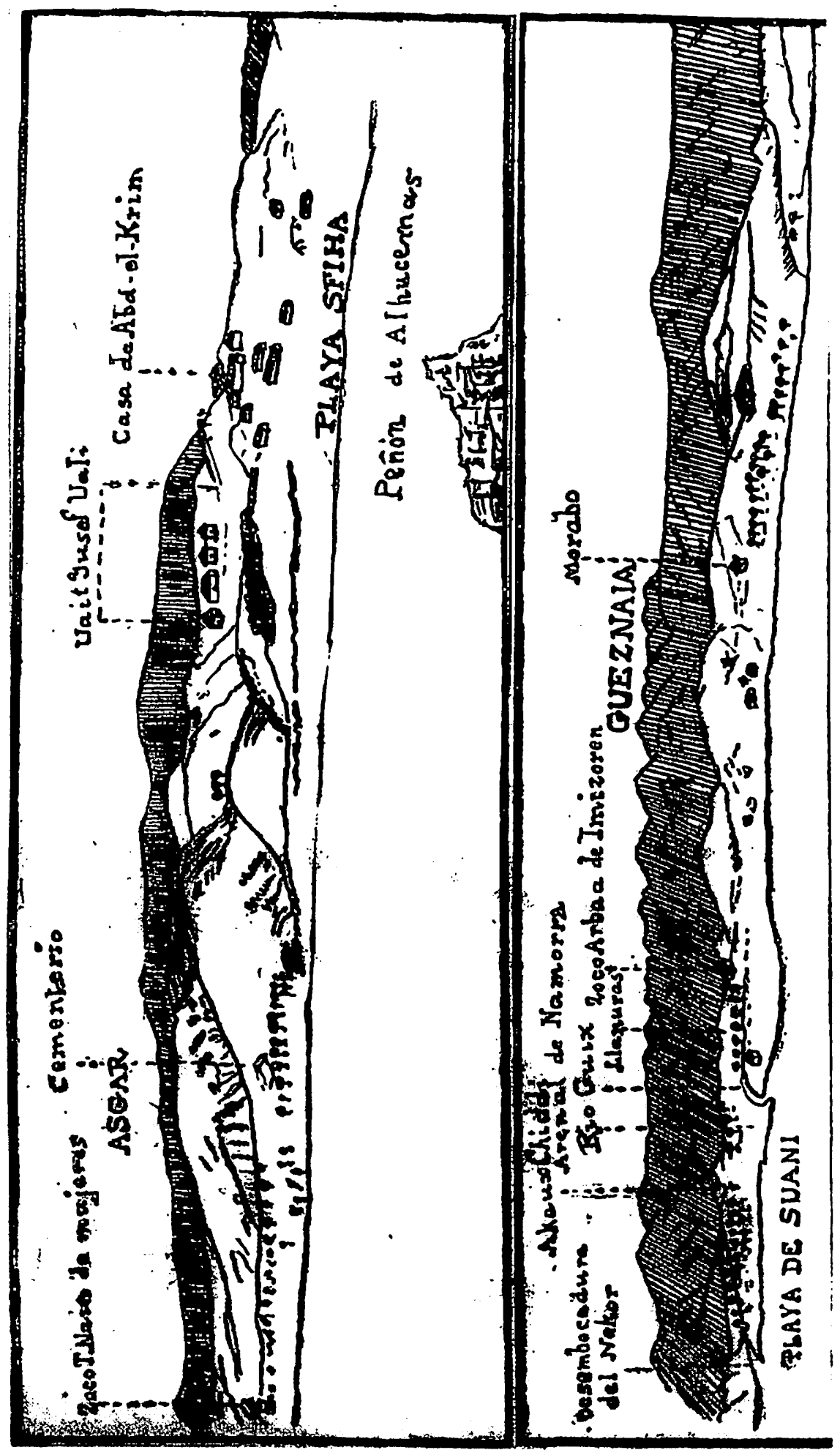


sino que precisamente, el conocimiento de los valores de nuestra civilización, ha llevado a los indigenas a rechazarla por inmoral y despreciable,porque no hemos respetado los ideales vigentes en nuestras culturas desde la Revolución Francesa.No es por tanto una resistencia derivada de un independentismo salvaje e ignorante. La prueba es que hemos permitido que los caides fueran elegidos popularmente y al mismo tiempo hemos seguido cobrando tributos y violando los derechos que debían ser respetados.

Alhucemas, ha supuesto, según José María Sevillano, la rehabilitación de nuestro prestigio militar, después del desastre de 1921.Ha demostrado la capacidad guerrera de nuestras tropas. Todo ello ha sido posible por la combinación de tres elementos:el control por Primo de Rivera del dinero, del gobierno y del ejército. En este sentido explica al lector cómo es el momento de recopilar estadísticas, datos y narrar los hechos para que los historiadores del futuro sin el apasionamiento de los espectadores próximos puedan ponderar el hecho histórico en sí.Entre sus secuelas sobresalen la destrucción de la República del Rif, la ocupación de Axdir, su capital, y el dominio de los riachuelos de Nekor y Guis;vitales para la comunicación de nuestro Protectorado.

Otro factor que contribuyó al éxito de la operación conjunta de Alhucemas fue el apoyo del sultán de Marruecos; que puso precio a los cabecillas de la rebeldía, y condenó con la perdida de los derechos de propiedad rústica y urbana, a todos los que se opusieran al avance de las tropas españolas. La clave del triunfo ha sido la combinación de la velocidad, la economía y el utilitarismo. Matiza sin embargo que la intervención franco española se realizó sin el consorcio de la Sociedad de Naciones pues dicha institución carecía en esos momentos de un ejército fuerte multinacional para imponer sus decisiones. No oculta el cronista su admiración por el país vecino, Francia que sabe defender los derechos humanos y encontrar el hombre adecuado para cada momento.Muy especialmente elogia el exaltado patriotismo que la fina sensibilidad de Petain ha convertido en una excelente propaganda de la operación militar.Hecho que contrasta con la impopularidad que tuvo la empresa militar en España.

A juicio de Menipo la ideología nacionalista no muere con Alhucemas sino que se reconduce con nuevos criterios pues en las universidades y mezquitas de todo el Magreb, se sigue alentando la independencia. Del colaboracionismo con Europa,los nacionalistas piensan que el Islam saldrá fortalecido como lo prueban los aplausos que el pueblo dispenso a las tropas indígenas en Tetúan el día de la proclamación del Jalifa. Sus nuevos valores: la fe, la fuerza, la sabiduria, la justicia y el apoyo extranjero serán el principio de su resurrección, según comenta el Jalifa Mehdi, a su esclava Fathma. ${ }^{4}$

4 MENIPO,"Consideraciones.La lección del Islaın",23-9-1925;"Luego vendrá la historia",10-10-1925;"Las cosas en su punto",19-5-1927;

MARiN ARCE, J.M. "Primo de Rivera y la República del Rif durante los primeros años de la Dictadura.Las negociaciones con Abd el Krim en junio de 1925".II Congreso Internacional del Estrecho de Gibraltar.Madrid, 1995, p.271-6.En el Convenio sobre Tánger de 1924 se prohibe a España mantener establecimientos militares een dicha ciudad,lo que favoreció que los agentes de Abd el Krim pudieran enviar suministros, dinero, y armas al Rif.La oficialidad española fue contraria al repliegue ordenado por Primo de Rivera pues a su juicio permitiría el levantamiento de las cabilas de la zona occidental.Abd el Krim aprovechó para reclamar las fértiles tie- 
En las primeras crónicas 1926 continua argumentando las claves del éxito franco-espiñol de Alhucemas.Se unen en esta ocasión el deseo compartido de Francia y España por recuperar su prestigio de grandes potencias y ahorrar vidas humanas por ambos bandos con el de anular la superioridad material de las armas de los rifeños, suprimiendo el estado politico de la República del Rif.Alhucemas ha demostrado que el cabecilla rifeño sólo contaba con su Estado Mayor. El aminoramiento de las ayudas extranjeras,y el bloqueo que dificulto el abastecimiento de viveres y armas,propicio la sumisión de los indígenas. Alhucemas ha sido un operación militar bien preparada con sobrantes de materiales, viveres, y hombres; un Estado Mayor trabajador y competente, jefes prestigiosos con capacidad militar y creencia en el triunfo. En la consecución de los objetivos, Menipo no sabe que admirar más si la distribución equilibrada de las columnas o la utilización adecuada de fusiles, granadas de mano, artilleria, bateria de obuses, y aviación en la guerra.Palabras similares son empleadas por el profesor Morales Lezcano en referencia al desembarco del 8 de septiembre, cuando dice que el mando conjunto hispanomarroqui pone fuera de combate a la inquietante República del Rif en una campaña, la de los años 1925-26, donde se usó la experiencia bélica de la primera guerra mundial en los frentes europeos, y se preconizó el Kriegspiel, es decir, la guerra como materialización de un proyecto de gabinete militar que busca en la rapidez, la eficacia y la baratura, los criterios que inspiran las maniobras.

Por ello, finalizadas las operaciones militares es necesario un cambio de mentalidad. Las intenciones del gobierno español deben encaminarse según Menipo no a aniquilar enemigos sino en atraer consumidores para nuestros productos manufacturados. Hay que hacer participe al indigena del bienestar material de que disfrutan en la zona francesa los súbditos de Tánger, Casablanca, y Rabat. Cuando se vayan los militares deben llegar hombres del campo, que pongan en cultivo las tierras estériles o incultas. Debemos mejorar los transportes y las comunicaciones para que los excedentes de alimentos lleguen a cualquier lugar del planeta. Hay pues que conectar su economía con los circuitos mundiales, y convertir a Marruecos en un pais de exportación para asegurar el mantenimiento de una población en crecimiento. El bienestar material podría anular en cierto modo el carácter de guerrero indisciplinado del marroquí, aunque en España esta táctica sea dificil de comprender.

En mayo de 1926, entretiene a los lectores españoles comentándoles, los incidentes de las operaciones de la Cala del Quemado. Describe con minuciosidad el avance de los soldados de las harkas de Yalif y Erquicia,que soportan en primera línea, el fuego de artillería, y la ocupación de los morabos por los Regulares de Melilla y los Cazadores de Africa.En el asalto a la Loma del Cañón explica como se reforzaron las guarniciones de las casas más próximas del enemigo, mientras el Tercio ocupaba la margen izquierda del Guis, para extenderse a la Vega. Estas acciones permitieron la ocupación de la playa de Suani y el Nekor.

rras del rio Werga lo que provocó la ruptura de negociaciones con Francia, y el ataque del cabecilla rifeño a la guarnición de Bibau, al norte de Fez.Estas circunstancias facilitaran el acuerdo hispanofrancés que dará como resultado el desembarco de Alhucemas. En dicha operación participaron 32 buques de guerra españoles y 18 franceses amén de otros navios mercantiles.El lugar fue la playa de la Cebadilla en la península del Morro Nuevo.Fue simultáneo a la ofensiva francesa contra los rifeños en la linea del Werga. 










A diferencia de las operaciones de 1922, ahora es posible recorrer el territorio conquistado sin protección armada pues se ocupan las casas rebeldes distribuidas en torno a un patio corral, se vuelan los polvorines, y se incautan los cañones. Hay un mayor rigor en la información de la guerra gracias a la que suministra diariamente la aviación del Comandante Gallarza sobre el avance de las columnas y los problemas que tienen los franceses en sus fronteras. No olvida Menipo resaltar la cobardía y traición de los musulmanes, que huyen ante el avance, carentes de honor militar, y como sus continuas cambios de opinión y bando, han obligado a una guerra sin cuartel. La ocupación de las cortijadas y de los pastos de la zona aseguran la alimentación de la tropa y del ganado. En sus escritos se destila un cierto recelo ante las continuas sumisiones de algunas cabilas, que informan a las tropas españolas de la ruina en el campo rebelde y el desconcierto de Abd el Krim con objeto de pasarse a nuestro bando aunque dudan si finalmente negociaremos con él o continuaremos la gue$\mathrm{rra}^{5}$.

El encendido apoyo que presta el cronista a la guerra en estos momentos lo justifica ante sus lectores explicando las razones de su defensa del abandonismo en años anteriores, durante la campaña de Yebala. Recuerda que se mostró critico con la capacidad militar,los prestigios consagrados, e incluso llegó a reconocer la superioridad espiritual del enemigo. Los motivos de su abandonismo fueron el miedo y la inseguridad, existente en esos momentos, en el Protectorado. Su actitud ha cambiado porque ahora se ha introducido una nueva estrategia, aunque falta todavia un núcleo expedicionario de 60000 hombres y la organización de cinco columnas en la zona occidental, que aseguran el enlace con la oriental.

La sumisión de Tensamani, obra de Sanjurjo, es a su parecer una operación secundaria frente al objetivo inicial de la campaña: el control de Beni Urriaguel, que ha permitido ocupar la meseta de la cabila con sus cortijadas, morabitos y bosques. La clave estuvo en la decisión arrolladora frente al "chau chau" de los años anteriores en los que había que recorrer el terreno con protección armada; opiniones que vertidas en la prensa le acarrearon ser considerado como abandonista. Menipo llega a poner en duda el criterio final del mando en estas operaciones, actitud por la que es de nuevo censurado. El desarme de las cabilas de Tensaman y Beni Tuzin, aseguran el viaje en acemilas desde Morro Nuevo a Azib el Mider.

La victoria española se debe también a que el ejército contó con jefes prestigiosos como el teniente coronel de regulares de Ceuta:Varela. Al entrevistar a este jefe militar,después del éxito de los morabos y de la reducción de Abd el Krim en Taza, José Maria Sevillano, acerca al lector al ser humano.Varela, hombre modesto y valiente, atribuye sus triunfos al soldado de infanteria español: Medialdea, San Juan,y Cardeñosa. El cronista reflexiona sobre las palabras escuchadas y piensa que Varela, un valiente, medio hambrien-

5 SEVILLANO, J.M., "El Noticiero en Marruecos.La campaña de Beni Urriaguel", 18-5-1926; "Notas de la campaña", 23-5-1926; "De la campaña de Africa.Estado actual del problema", 25-5-1926; "Notas de campaña.Diálogos de retaguardia", 1-6-1926; El Noticiero Sevillano, 1926; MENIPO, "Consideraciones. Ahora es la propia hora", 5-1-1926; MORALES LEZCANO, V., España y el Norte de Africa. El Protectorado de Marruecos. (1912-1956). Madrid, Uned, 1986.

GONZÁLEZ CALVET M.T., "La defensa del Estrecho y la pacificación del Protectorado Marroqui en la politica del general Primo de Rivera". II Congreso Internacional del Estrecho de Gibraltar. Ceuta. Madrid-1995, Tomo V, págs.287-298. 


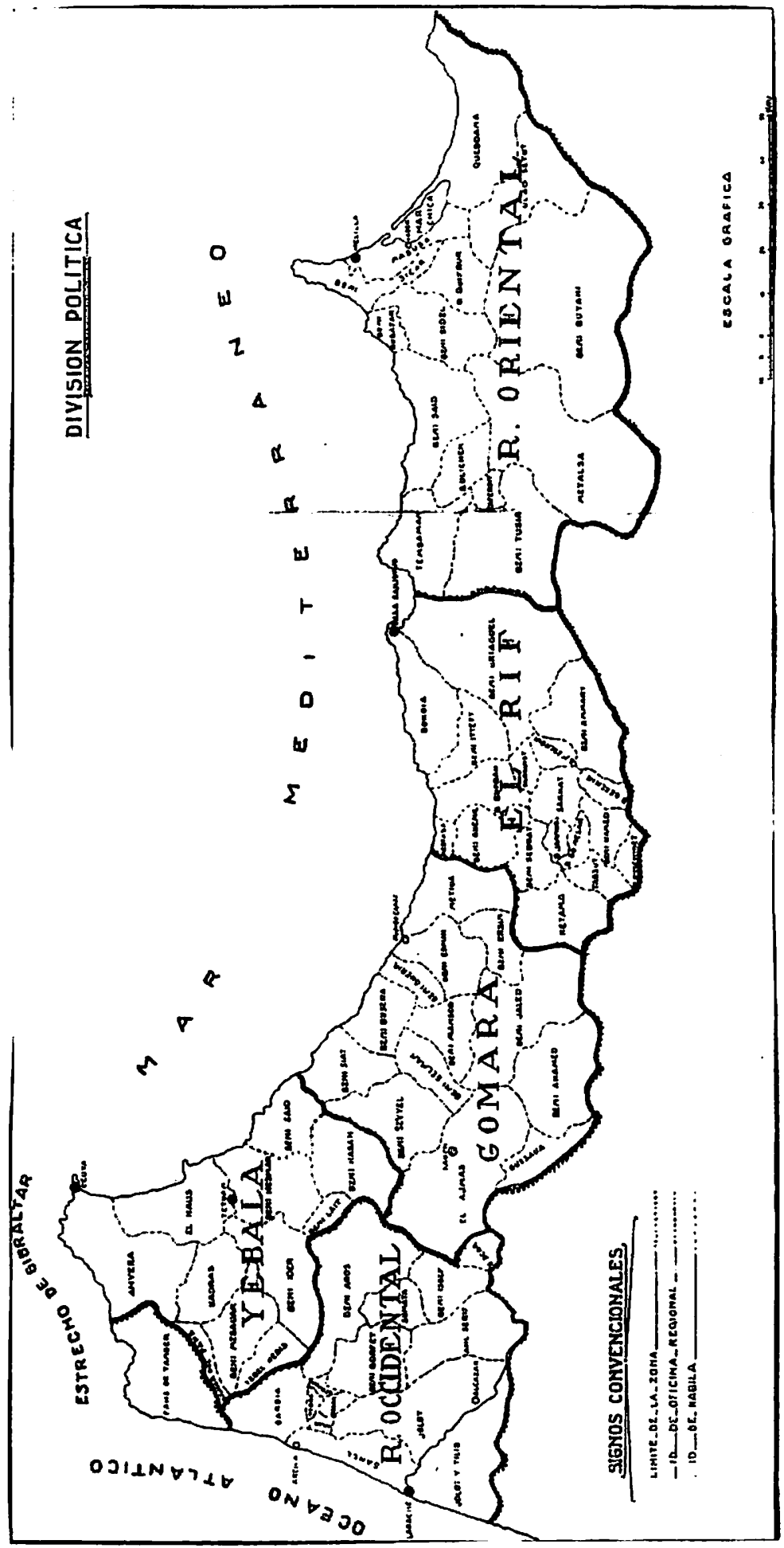


to $y$ gallardo militar, tiene prestigio y humildad suficientes para un ascenso aunque aumenten sus enemigos entre los militares de la Península, contrarios a la modificación que en 1924 se hizo a la ley de 1918 que favorece a los africanistas, partidarios del ascenso por méritos. ${ }^{6}$

Entre las consecuencias de la campaña en la zona oriental subraya Menipo la imposición de la forma de vestir y de trabajo europeo a los indígenas evitando que las mujeres aunque vistan a la europea no abandonen su función reproductora y copien a las feministas europeas. La ocupación española del Rif causó entre sus habitantes una gran inquietud espiritual.Estos grupos humanos algo distintos de los elegantes y sumisos habitantes de Yebala, precisan un trato diferente ya que están acostumbrados a obedecer a un cacique, apoyado en aventureros y guerrilleros no en una elite caballeresca. En este sentido, José Maria Sevillano opina que una mayor urbanización de la zona favorecería la asimilación por los rifeños de la cultura europea. Hay que interesarlos por los negocios pero evitando que uno de los jefes acumule más poder e influencia que los demás. De este modo la vida de los rifeños mejoraría pues se cultivarían sus campos, se trataría mejor a sus mujeres suprimiendo el concepto de mujer carga, e incluso se reconstruirían las viviendas destruidas en la guerra.La rendición de Abd el Krim a los franceses suscitó una enorme polémica en toda España.José María Sevillano considera que este es el momento de juzgarlo por sus crueldades y delitos contra el derecho de las gentes, no por dirigir un movimiento de rebeldia en favor de la independencia. Su comportamiento no ha sido digno de una persona civilizada, que ha estudiado en Europa. Desgraciadamente su denuncia fue de nuevo censurada.?

Sometida la zona oriental, el ejército español retoma la ofensiva en la zona occidental, donde hay que reducir la actividad del Jeriro en Beni Hosmar y recuperar Xauen.Para controlar la zona es preciso tener en cuenta la influencia política, religiosa y militar de Beni Aros, y la realidad económica de una zona falta de pobladores aunque con abundantes pastos. En agosto de 1926 las tropas españolas logran la rendición del hijo de Raisuni, procedente del Peñón Vélez de la Gomera. Durante la guerra se respetan las tumbas de los santones del Islam como Sidi Yusef. La primera gran victoria fue la entrada del ejército español en Xauen. Menipo nos comenta la estrategia usada por las tropas mixtas indigenas y españolas, que distribuidas en tres columnas reducen Xauen,y vigilan Zoco el Arbáa y Ben Karrik. La ciudad sagrada será el punto de encuentro de Castelló, Varela y Capaz. La ayuda de la aviación se mostró en esta ocasión vital.Sin embargo, a diferencia de lo ocurrido en

6 SEVILLANO, J. M., "Notas de campaña.Jefes de Vanguardia. Varela", 4-6-1926. El chej es el jefe de cada fracción de las cabilas. El Jalifa está asistido por su gobierno que se llama el Majzen jalifiano. El territorio se divide en caidatos gobernados por un caid que controla a varias agrupaciones indigenas o cabilas. Cuando en la jurisdicción de ese caid existe alguna ciudad se llama a ese territorio, bajalato, y a su gobernador, bajá. En cada cabila hay un ministro de justicia, otro de hacienda y un visir. El Jalifa es el jefe del gobierno y de la administración que goza en el Protectorado español de los mismos derechos que el sultán en su territorio.

7 SEVILlaNO, J. M., "Crónicas de Marruecos. Al final y al cabo,la mujer", 29-6-1926; "Nolas de Campaña. El avance prosigue". 6-8-1926; "El proceso de Abd el Krim", 18-6-1926; "El Noticiero en Marruecos"; "La situación militar y política", 24-8-1926; "España en Marruecos. Después de la guerra", 17-6-1926; "Los quinientos hijos de Beni Urriaguel", 27-8-1926; "El Noticiero en Marruecos. Ya estamos en Xauen", 14-8-1926. El Noticiero Sevillano. Sevilla, 1926. 
Alhucemas, el ejército español continúa sin tener sensación de dominar la zona pues desconocen cuál será la respuesta de los cabileños al desarme.Menipo lamenta que en esta zona no sean $\tan$ efectivos los procedimientos usados en el Rif al quedar a retaguardia, flancos enemigos. Reconquistado Xauen y reducido el Jarero, sólo es necesario un acuerdo político para rematar la ocupación militar.

Pasa más tarde a comentar otra de las claves de la victoria que fue la utilización de las harkas indigenas.En este sentido José María Sevillano reflexiona sobre los procedimientos seguidos por López Bravo y Capaz para obtener tan buenos resultados con los 500 de Beni Urriaguel, antes al servicio de Abd el Krim. La respuesta de su jefe Budr, que hizo las campañas de Anual, Xauen y Xarga al periodista, subraya cómo luchando en las harkas, ellos no traicionan a nadie, sino que trabajan por su país. La misión de la harka fue siempre la de inspeccionar y administrar las zonas, al frente de sus propios caides, y con la ayuda de la aviación. De esta forma se crea entre los rifeños una conciencia nacional contra el Imperialismo europeo, paso previo para la emancipación'

El desarme de la zona fue una de las tareas más dificiles de ejecutar por las tropas españolas por la constante sangria de huidos a la zona francesa y las vacilaciones de los chej de los aduares a la hora de entregar los Remington, Chossepot y Mauser.Menipo piensa que da la impresión de que hay un acuerdo tácito entre jefes y bandoleros contra España. A veces, se comportan como sí fueran príncipes a los que no les importa pasar hambre y otras penalidades con tal que mantener su capacidad guerrera. La lentitud del desarme es el motivo que en opinión del cronista impide el control absoluto de la zona occidental. Para comprobar su seguridad, José María Sevillano hace un viaje en burro desde Tetúan a Melilla, similar al realizado por el General Sanjurjo con la única escolta de un escuadrón del tercio.Los resultados son dispares pues los periodistas españoles y extranjeros encuentran pequeñas resistencias contra la ocupación española en Beni Ider, que no pueden ser acalladas por falta de tropas,de dinero,y por la lentitud del desarme.Las continuas hostilidades en la zona obligan a una nueva campaña en noviembre de 1926. Esta vez las lluvias otoñales y el frí dificultan las operaciones que terminan con el éxodo de los habitantes de Beni Ider hacia el sur, la muerte del Jeriro, el recorte del presupuesto, y la repatriación de las tropas sin acabar la campaña.En las operaciones contra la zona dirigidas por el Cuartel General hay una visión amplia y completa de la guerra que ha permitido al general Goded llegar hasta el collado de. Afernum.

Al comenzar la campaña de Beni Aros, el periodista explica a sus lectores el espacio fisico en el que se desarrollan los acontecimientos. Se trata de una fortaleza natural, de gran potencial hidrológico, pues alli fluyen el Jarrud, el Majazcen, el Lucus, el Menzora, y los

8 SEVILlaNO, J. M., "El Noticiero en Marnecos. De Tetúan a Melilla en burro I", 6-10-1926; "De Tetúan a Melilla en burro II", 9-10-1926; "La campaña sobre Beni-Ider. La jarka de los rifeños. El Jeriro ha muerto", 9-11-1926; "Esperando que hablen los jefes internacionales", 8-9-1926; "Algo ha cambiado aqui", 10-111926; "De Benkarrich a Xauen", 18-8-1926; "Las dificultades del desarme", 2-9-1926: "Croquis de Beni Arós", 24-11-1926; "Las fuerzas indigenas", 26-11-1926; Monsieur Steeg en Tetúan, 3-12-1926. \El Noticiero Sevillano.

AMIGO Eladio. Marruecos. Ideario político-militar. Tenerife, Imprenta Bethencourt, 1928. 
tributarios del río Martín. La visita de Mr.Steeg a Tetúan,en el Protectorado Español obliga a debatir los temas planteados en el Tratado de Madrid y en particular cómo resolver la vigilancia de las cabilas que están a caballo entre ambos protectorados teniendo en cuenta que desde las que asoman al Uarga que llevan hasta Fez partió la rebeldia de Abd el Krim. La idea es no dejar al descubierto la defensa de la zona española. ${ }^{9}$

La pacificación del Rif y del Yebala pusieron de manifiesto según Menipo la eficacia del Estado Mayor y de las nuevas estrategias.En ellas, se combinó la ciencia militar con el derecho musulmán. En un solo mando se integraron los oficiales que saben de Geodesia y Alta Estrategia con el Tercio, los Regulares, y la Intervención,conocedores de la ética marroquí.El último artículo de este año plantea a los lectores cual debe ser ahora la misión de España finalizado el problema militar.El ideal sería explotar sus riquezas para obtener un adecuado rendimiento pero faltan industrias, mano de obra cualificada, y ferrocarriles.

Una de sus reflexiones más sugerentes es la que hace del origen, procedencia, tipologia, y administración de los Bienes Habus. Según la información recogida por el cronista se remontan a los tiempos de Mahoma y los Califas Perfectos, quienes determinaron que a su muerte, las personas que administrasen estos bienes, disfrutan de una parte de la renta.Es por tanto una institución, vinculada a los tiempos de la conquista árabe, cuyo régimen de explotación se perfecciona en tiempo de los almohades y los benimerines cuando se produce la crisis del poder central.Los años anteriores al Protectorado (1912) fueron tiempos de dilapidación y usurpaciones. Estos bienes son de dos tipos; los pertenecientes a los sepulcros de los Chorfas o morabitos, es decir de los santuarios que se levantan sobre las tumbas de los santones, a donde se celebran anualmente amara o peregrinaciones, y los bienes de las mezquitas, constituidos por legados que al morir hacen personas notables en favor de las comunidades religiosas. Son bienes inalienables aunque el encargado puede arrendar los terrenos de labor.En 1926,el $80 \%$ de la riqueza rústica y urbana era comunal, administrada por una Junta de Notables, que repartía los beneficios entre el culto, la guerra y la beneficencia.El trabajo se distribuía entre los aptos pero su destino es la comunidad no una minoría como en el sistema capitalista.Por ello, analizando el sistema desde la óptica marroquí resuelve el problema de la alimentación básica de toda la sociedad.

Menipo compara la administración de los bienes habús en la zona española y en la zona francesa donde el visir de los Habus propuso al Consejo Superior de los Ulemas una reforma adecuada de estos bienes para proporcionar recursos suficientes a la comunidad para mantener el culto, la administración de justicia, la enseñanza, y la beneficencia. En el Protectorado francés, los beneficios de su explotación, permitieron realizar el mercado de Rabat, los nuevos barrios obreros de Casablanca y el Splendid Hotel. Incluso el Ministro de los Habus con la ayuda del "Service du Controle" ha elaborado un Registro de inmuebles,

9 SEVILLANO, J. M., "El Noticiero en Marruecos. El huevo de Colón”, 9-12-1926; "Un comunismo ignorado", 21-12-1926; "La seguridad en el campo", 31-12-1926; Cuando los bienes habus pertenecen a un morabito la familia del santificado tienen derecho a una parte de los intereses y los bienes se dedican a la manutención de la comunidad y al culto. 


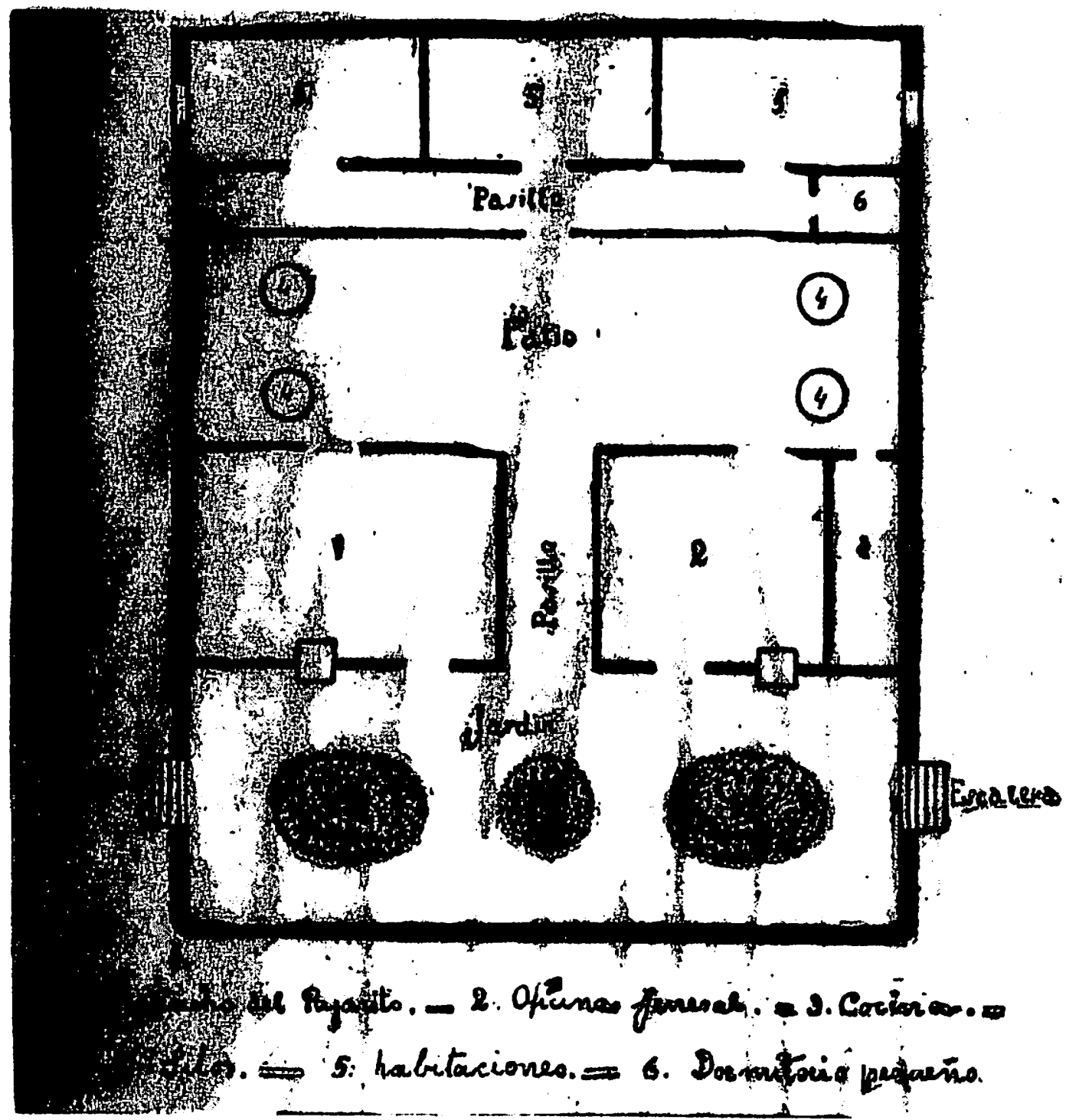


donde se anotan los gravámenes y derechos adquiridos, logrando recoger de los Nadires un buen número de donaciones que hoy ser archivan en las Cajas Fuertes del Visirato de los Habus. En ambas zonas Menipo es partidario de ceder la administración de estos bienes a los marroquies, que una vez capacitados como funcionarios evitaran la dilapidación y distribución de forma imparcial de tan cualificados recursos. ${ }^{10}$

En 1927, aún continua insumisa buena parte del Yebala, donde se está procediendo al desarme, para lograr una ocupación efectiva y total, sin reservas mentales, ni traición posible. La división de los jefes de la zona, de los que sólo queda de importancia el Hartiti, caid de Raisuni en Beni Hazmar, y las posibilidades de controlar Tánger, único medio de evitar el contrabando de armas por la Bahía son factores a considerar para acelerar el final de la campaña. José María Sevillano desea convertir Tánger en un centro de soldados y funcionarios, expulsando a los croupiers, tanguistas y aventureros. En abril de 1927, un grupo de rebeldes ataca a las tropas francesas y españoles en las cabilas fronterizas de Ketama, Beni Zerual y Beni Jaums. Contrastada la información con diversas fuentes Menipo comenta a sus lectores que el alaque principal se ha producido contra las líneas francesas, donde el desarme se realiza más lentamente, cómo la prensa ha exagerado la dimensión de los enfrentamientos y la conveniencia de retrasar la campaña de Yebala para ayudar a los franceses en su lucha contra los rebeldes de Ketama.

Haciendo un pequeño balance de la situación, en 1927, las tropas españolas, habían logrado la sumisión de Beni Urriaguel, el control de Xauen y Gomara, y estaban a punto de unir las dos Comandancias de Melilla y Ceuta.Quedaban solamente dominar Beni Aros, Sumata y Jomas al Norte, $y$ las tribus fronterizas en la línea de separación de ambos protectorados, al sur Beni Ahmed y Guezana.Ello nos llevaria a unir Xauen y Larache por Dra el Asel. Castelló controlado Xauen, ha asegurado la neutralidad de Jomás, Capaz ha extendido su influencia hacia el sur, y Ostariz ha intentado penetrar en Ketama, zona bien distinta a las anteriores, con altas cotas, y valles, que nos recuerdan el mundo alpino europeo. Una zona, falta de unidad geográfica.

Para animar al ejército español en estas últimas operaciones militares, el presidente del Directorio, Miguel Primo de Rivera viaja a Tetúan y Ceuta donde en compañia de Sanjurjo observa los estragos producidos por el temporal de nieve, y las bajas, producidas en el encuentro con el enemigo. Menipo recuerda como de no haberse repatriado las tropas tras Alhucemas no hubieran ocurrido estos incidentes.Este revés no ha sido tan importante como el de Abarrán porque las cabilas a retaguardia estaban desarmadas. Todo ello obliga a pensar en el ideal del desarme para controlar Beni Aros, Sumata y Jomas.

En sus crónicas sobre la Campaña de Zoco el Arbáa de Tazangarth se asombra de la rapidez con que avanzan las tropas y se amontonan los refugiados en la zona francesa. Relata como los disidentes marchan con sus familias, enseres y ganados aunque a veces no siem-

10 SEVILLANO, J. M., "Los Bienes Habices y el Service du Controle 1", 5-1-1927; "Los Bienes Habices y el Service du Controle II", 8-1-1927; "La nueva campaña de Yebala", 26-1-1927; "La ofensiva general contra los disidentes", 13-5-1927; "Los temporales y la visita del Presidente", 16-4-1927; "La situación verdadera", 7-41927; "El Noticiero en Marruecos. Las cabilas de la frontera", 2-4-1927; El Noticiero Sevillano. Sevilla, 1927. 
pre disponen de recursos para atender a sus necesidades más elementales. La resistencia de los rebeldes de Anyera y Beni Hozmar a entregar el fusil hace pensar a Menipo si no sería más conveniente cambiar de estrategia quizás usar la psicología para convencerles que el fusil es más su perdición que su salvación. Insiste en que para la movilidad de las tropas y un efectivo control de la zona es preciso la unión de Xauen, centro de comunicaciones con el mar, por ferrocarril, y con Melilla, Larache y Tetúan por carretera.

Menipo reconoce que tiene una cierta desconfianza sobre el entusiasmo del pueblo hacia esta nueva ofensiva militar.En 1909, era comprensible que la presión popular no quisiera las viudas y huérfanos que había acarreado nuestra política de dar dinero a los rebeldes, porque la democracia y los partidos de izquierda eran contrarios a la acción militar en Marruecos.Esa inactividad se debió a la torpeza, ineptitud y venalidad de los gobernantes, y al propio sistema democrático que impuso la opinión de la masa sobre la minoría.Esto no quiere decir que la Democracia sea un fracaso sino que España no estaba preparada para ello pues un pais apto para dicho sistema hubiera comprendido la utilidad de Marruecos y hubiera ayudado a resolverlo cuanto antes. En 1927, el pueblo continua, pese a que el triunfo ha acompañado en esta ocasión a la empresa, sin entender la solución dada por la Dictadura de Primo de Rivera al problema.Alhucemas ha demostrado que Marruecos era una mentira inventada por los políticos ${ }^{11}$.

La campaña de Sumata permite al cronista retomar el tema ya antiguo de los renegados.Se trata de españoles que abandonaron el ejército y se han adaptado al estilo de vida musulmán.Podemos conocerlos por el ceceo, por la perfección con que hablan el castellano y lo bien que manejan el mauser.En sus crónicas de la guerra de Sumata explica la relevancia que han tenido los coroneles Castelló y Balmes en Tesef y Tahar, y cómo han utilizado los afluentes del Mejazen como vías de penetración en el territorio.El primer enfrentamiento con los rebeldes en el Collado de Akerzam no registró bajas notables.Por tanto, la zona sometida está siendo confiada a interventores militares, cuya misión será finalizar el desarme, y organizar columnas de vigilancia en las que paulatinamente se integraran los indígenas.Uno de los últimos reductos rebeldes fue el morabito de Sidi Mesaud. A juicio de Menipo, una concepción estratégica de la maniobra, dirigida por el Estado Mayor, la especialización de las vanguardias, y el entrenamiento de las fuerzas indígenas, Tercios y Cazadores de Africa han sido las causas de éxito militar. La recogida de unos 200 fusiles en la cabila de Jomás demuestra la efectividad del desarme.

Resulta curioso señalar la estrategía empleada por el ejército español, aconsejado por Dris el Riffi, bajá de Arcila para reducir el foco de resistencia de Yebel Alan, donde está el morabito de Muley Abdeselam.Esta consistió en convencer a los chorfas, santones y guar-

11 SEVILLANO, J. M., "La invasión y el castigo de Sumata", 21-5-1927; "El Noticiero en Marruecos. La verdadera ocasión para la percalina", 3-6-1927; "El Asalto al Yebel Alam", 22-6-1927; El Noticiero Sevillano. Sevilla, 1927. A los enterrados en el Yebel Alan se les conoce con el nombre de Chorfa Alami y sus familiares estan dispensados de pagar tributos. El morabito más venerado es el de Muley Abd es Selam enterrado en el Yebel Alan o Monte de la Señal pues según la leyenda cuando lo enterraron no pudieron ocultarle uno de los brazos se quedo fuera por sus profecias a manera de señal. Es famoso por sus romerías. El santón Muley predijo que la bella y santa ciudad de Tetúan seria tomada por los cristianos. AMIGO, E., op.cit. págs. 32-33. 
dianes de las reliquias, de que nadie amenaza sus creencias religiosas. Para demostrarlo, las tropas españolas custodiaron a los peregrinos que en unión a sus caides iban en peregrinación a dicho santuario. De esta forma el ejército intento ridiculizar a los fanáticos Muyaheddin a quienes interesa más ganar dinero que la oración, y desvirtuar la propaganda que consideraba al ejército español poco respetuoso con la religión musulmana.Los resultados fueron los esperados. La columna de Balmes asaltó el Macizo por el Oeste, otra con las tropas del Jalifa avanzÓ desde Telata de Beni Ider y la columna de Canis controlÓ Bad Stha. Al poco tiempo, la bandera española dominó el Yebel Alam, y junto a la bandera del Majzen, ondean juntas en el pico más alto del Buhacen. El Comandante López Bravo aprovecha la ocasión para atraerse a muchos harqueños a la tropa, y Capaz con la ayuda de la aviación, desarma los aduares entre Ketama y Beni Hamed pese a las dificultades del terreno. ${ }^{22}$

A finales de julio, el territorio está pacificado y la acción militar va concluyendo por lo que José María Sevillano se pregunta si habrá hombres civiles que sustituyan a los militares y empiecen una nueva acción que convenza a los musulmanes del fin de la dominación militar.La situación actual permite que el campo quede libre de posiciones y blocaos, pues las mejaznías de los caides y los yemias de los chejs del aduar, garantizan la seguridad de los caminos.Ahora si es posible la repatriación de las compañías expedicionarias dejando las fuerzas de ocupación reducidas a lo mínimo. No obstante, estima conveniente mantener una línea de posiciones en la frontera porque en el Protectorado francés el desarme va más lento, y no se ha puesto fin al contrabando de las armas desde Tánger. Ejemplo de este contrabando activo es la confesión de uno de los últimos rebeldes Uld Ayana a los militares a quienes se entregó en el campamento de la mejala de Dar Xaui.Este hombre de facciones elegantes y bereberes aseguró que nunca le falto el apoyo de Tínger, aunque fue el fracaso del complot comunista en dicha ciudad en favor de la emancipación de las colonias y la falta de viveres e ideales de lucha, lo que decidió su rendición.

La pacificación de la zona occidental y el dominio del Rif hacen posible en octubre de ese año la visita de los reyes de España a Ceuta, Tetuán, y Riffien. Ceuta se presenta ante los reyes como una ciudad bien fortificada y resguardada por las baterías del Hacho y la aviación. Tetuán rivaliza con la primera en españolismo. Los Reyes admiraron su alcazaba, pasearon por el barrio moro,y visitaron la Hípica y el Palacio de la Residencia. Desde los montes cercanos el Rey contempló las zonas recién sometidas de Fondak, Ben Karrich, y Beni Hassan. En Riffien tuvieron la oportunidad de conocer al Jalifa, al Majhzen y a los caides de Yebala ${ }^{i 3}$.

12 SEVILLANO, J. M., "El Noticiero en Marruecos. El aprovechamiento de los ex-cabecillas", 28-9-1927; "El momento delicado del tránsito", 13-7-1927; "Hacia la liquidación final", 1-7-1927; La visita regia, 14-101927: MENIPO, "Consideraciones. Viajeros ilustres", 8-10-1927. El Noticiero Sevillano, Sevilla, 1927.

13 MENIPO, "Consideraciones. El punto de vista marroqui", 1925; "El regreso de los aviones", 1925. "La cabeza del cabecilla", 27-9-25; "Películas marruecas. Las tropas indigenas triunfan", 20-11-1925; "Consideraciones. El ejemplo de Asia", 5-2-1927; "Cartas de Otmán. Viajar es aprender", 9-1925; "Consideraciones. La lección del Islam", 23-9-1925.

SEVILLANO, J. M., "El Noticiero en Marruecos. Final del Ramadan", 17-4-1927 


\section{EL NACIONALISMO MARROQUÍ}

Son varios los artículos que Menipo dedica al tema nacionalista. Las tesis de Lenin contra el Imperialismo europeo y su defensa de la descolonización hace que muchos escritores de la época participen de ese temor al bolchevismo patente en los gobiernos autoritarios de los años veinte. En este sentido, el periodista hace participe al lector del temor del Directorio ante el intento de penetración del comunismo en la Península pues seria el causante del desorden de Europa y desestabilizaria políticamente España. El colaboracionismo entre la autoridad del Majhzen y los rifeños de Abd el Krim, estuvo a punto de trastocar los acuerdos entre España y Francia, y sólo se explica por la ayuda económica que recibieron de los Soviets y de Alemania.En Las nuevas cruzadas continua debatiendo la influencia del comunismo en la cabila de Abd el Krim;una ideología distinta a la predicada por Marx y Lenin, pero no por ello menos efectiva a la hora de actuar como agente destructor y propagandistico al servicio de Moscú. Los valores de solidaridad y disciplina que se desprenden de los teóricos del socialismo constituyen un peligro para el colonialismo europeo. La profesora Sueiro Seoane ya expuso en su día como Primo de Rivera trato con el desembarco de Alhucemas de frenar la difusión del comunismo en Marruecos. Es lógico que la república del Rif en su lucha contra el colonialismo europeo despertase las simpatías de la Rusia de Stalin, que sabía con certeza que las colonias eran el talón de Aquiles de las potencias europeas. La apuesta del comunismo por la emancipación de las colonias fue sin lugar a dudas el primer paso para la descolonización y la ruina de Europa. Menipo explica la pronta aceptación de estas ideas en el Magreb por la existencia de una muchedumbre ignorante, y deseosa de tierras fértiles, antes en manos de extranjeros y de caciques locales, y la división de Europa ante el avance comunista después de 1917. Tiene sus dudas sin embargo sobre si será posible la alianza de la aristocracia religiosa y la guerrera representada por Abd el Krim, defensor de las reivindicaciones sociales.Si esa conexión hubiera sido posible en ese momento, se hubiera avanzado a un segundo paso en favor de la libertad e independencia; condiciones imprescindibles para llegar a la unidad nacional. Una idea que ya había sido puesta en práctica con éxito en Turquía.

En Las Cartas a Otman expone la posible ayuda alemana a la sublevación de los indigenas con la idea de desestabilizar el Imperio Colonial Francés. Prueba de ello es la similitud entre la estrategia, los procedimientos bélicos y de combate alemanes y rifeños. El nacionalismo debe contar siempre con una sólida ayuda económica que en gran parte procede del contrabando de armas. Una realidad diaria como había comprobado el ejército español al incautar billetes franceses a los conspiradores y diversos tipos de armamento en los aduares. Menipo no oculta su indignación al descubrir las cuantiosas ganancias particulares que obtienen muchos capitalistas europeos de la venta de armas a la rebeldía rifeña.Las marcas Krupp, Scheneider, Einsaldo y Wickens demuestran la procedencia europea del armamento usado por los indígenas y cómo el armamento ha sustituido a la maquinaría agrícola que hubiera favorecido el cultivo de las tierras y mejorado las condiciones de vida de la población rifeña.El nacionalismo marroqul no es sólo una ideología difundida por los sacerdotes del Islam sino apoyada por las industrias europea que ven en esta rebeldía un medio de incrementar sus ganancias económicas. La flexibilidad del gobierno del 
Protectorado francés hizo que los rifeños tuvieran acceso a los mercados hasta 1924.En España la marcha de Silvela y el apoyo de los nacionalistas catalanes y vascos a la República del Rif suscitó las protestas de los militares contra Alba y acentúo el odio entre el pueblo y los políticos y la impopularidad de la empresa marroqui. ${ }^{14}$

En París, cabeza del Islam, José María Sevillano comenta la función de las mezquitas y del clero religioso islámico en la difusión del Nacionalismo. Un ejemplo es la ubicación de una mezquita en Paris en un moderno bloque de pisos. El encargado de la misma el cherif, Ben Moisa Abd Allah, agradece a la Republica francesa laica y socialista, las gestiones que han realizado en favor de dicho centro pues considera esencial que el espiritu religioso controle a las masas. El periodista en su conversación con el cherif, antes de su partida a la capital francesa, profundiza en las ideas que estan posibilitando una mayor tolerancia ideológica en Europa. Entre ellas,la morfologia de Spengler, el relativismo de Einstein y el psicoanálisis de Freud.

Menipo define a Tánger como centro difusor de las ideas nacionalistas debido a su doble condición de ser un centro cosmopolita, encuentro de aventureros y contrabandistas, y al escaso control que España tiene de las actividades inconfesables de la política mundial que alli se realizan. Es verdad que ha perdido parte de su valor estratégico en la vigilancia del Estrecho por la decadencia de los blocaos y las plazas tuertes frente a la eficacia de la aviación y los submarinos en la defensa. Pero continúa siendo el punto de partida del contrabando de armas y de ideas. Por ello, es vital que esté en manos españolas ya que sólo así tendríamos garantizado el desarme total en nuestro Protectorado. Tánger contó con un régimen especial desde 1923 que nunca obtuvo el apoyo de Italia y Estados Unidos. Esta situación se modificó en 1928 no logrando España el control que hubiera sido deseable para la tranquilidad del Protectorado.

La pacificación del Protectorado en 1927 no supuso el fin del nacionalismo. Gran parte del pueblo español desconfió de los éxitos militares y de nuestra permanencia en la zona conquistada creyendo que en un futuro no muy lejano el pueblo musulmán reclamaría su libertad. Uld Ayana, uno de los últimos rebeldes entregado comunica a José María Sevillano que los ideales no han muerto pero que se siente un cierto cansancio en la lucha. Este paréntesis durará hasta que de nuevo se unan las voluntades contra el Imperialismo extranjero siguiendo los ideales de libertad e independencia que se enseñan en las Universidades europeas.Otro ejemplo más de que la lucha sólo está adormilada pero no concluida es el secuestro de los parientes de Mr.Steeg a finales de 1927; un nueva táctica quizás de pueblo atrasado pero que refleja el odio al extranjero y la manera de obtener recursos para sostener la insurrección armada.

14 MENIPO. "Consideraciones. Paris, cabeza del Islam", 30-7-1926.

SEVILLANO, J. M., "El Noticiero en Marruecos. Los efectos del desarme, 24-4-1927; "El porqué de la indiferencia", 25-8-1927; "Los últimos secuestros", 1-11-1927.

DELGADO COBOS, I. y PAREJO DELGADO, M. J., José MaDelgado Garcia de la Torre. Menipo. Articulos periodisticos 1921-1934. Sevilla, Padilla Libros, 1997, págs.441-584.

PAREJO DELGADO, M. J., Impresiones Marruecas. Sevilla, Padilla, 1994. 
La nueva situación del Protectorado trató de facilitar la integración de las élites con las familias de los funcionarios, oficiales, y soldados españoles en Tetuán. Juntos practicaron el tennis y discutieron sobre las nuevas teorias filosóficas que se enseñaban en las Universidades europeas. La asimilación de las modas y costumbres occidentales no les hizo olvidar su verdadero objetivo:la emancipación de su pais. Este ideario, forjado en las Universidades, Cuarteles y Fábricas de Europa, se fue haciendo poco a poco realidad a medida que los europeos le descubrieron el valor material y espiritual de su territorio.

Este sentimiento de libertad es captado incluso por el pueblo español, que tras los exitos militares de 1927 desconfia del gobierno, y no se suma a la alegría general.Duda porque no sabe hasta cuando vamos a permanecer sobre lo conquistado pues un dia no muy lejano el pueblo musulmán reclamará su libertad.Incluso tras la entrega de Uld Ayana José María Sevillano, intuye el deseo de este rebelde de abandonar momentáneamente la lucha hasta atraer de nuevo las voluntades para continuarla con éxito.El secuestro de dos matrimonios en la zona fronteriza a finales de 1927 parientes de $\mathrm{Mr}$ Steeg explica cómo este pueblo atrasado en lo técnico expresa su rebeldía y odio al extranjero invasor de forma violenta al no contar con armas y recursos para una insurrección armada.Es, sencillamente un nuevo cambio de estrategia.

\section{CONCLUSIONES}

1. José María Sevillano-Menipo se comunica con sus lectores a través de dos personajes.Cuando ejerce como corresponsal de guerra, testigo en primera línea de los hechos militares, es un militar juicioso, que estudia las ventajas e inconvenientes de las distintas estrategias a usar en la ofensiva bélica.Utiliza el seudónimo de José María Sevillano, y aunque a veces se muestra crítico con el gobierno y el mando, se preocupa más de lo descriptivo, de señalar las diferencias con los tiempos de Berenguer y los motivos del éxito o la derrota.En un segundo grupo de artículos denominados "Consideraciones" opta por el planteamiento, nudo, y desenlace del problema a debatir; la situación de la mujer, la integración de las fuerzas indígenas en el ejército español, y las raíces del nacionalismo magrebi.Hay una ironía razonada en sus comentarios que avala con las ideas que por aquella época difunden las nuevas teorías filosóficas y económicas, el nuevo modo de ver el universo.Examina todas las variables.Por ejemplo cuando trata sobre el significado de Alhucemas, desembarco del que conmemoramos este año el setenta y cinco aniversario, emplea palabras elogiosas al frenar la rebeldía del Rif y permitir la rehabilitación de nuestro prestigio militar después de 1921.Felicita al Estado Mayor y se lamenta de la falta de apoyo de la Sociedad de Naciones.

2.El paisaje marroquí es para nuestro cronista una experiencia estética y sensual. Hace bellísimas descripciones literarias del relieve, la hidrografia y la vegetación. Novedosa es su actitud para la época en defensa de la naturaleza y en contra de las talas indiscriminadas y de los impactos de las operaciones bélicas. Su condición de militar hace que se fije en la disponibilidad del espacio para el ataque, la defensa, o la acampada.

3.Cuando describe las operaciones militares se fija en los aspectos estratégicos: uso de columnas móviles, disponibilidad de viveres y armas, planificación de la operación por el Estado Mayor, desarme de la zona que queda a retaguardia, utilización de las harkas indi- 
genas,y destrucción de los campos y viviendas enemigos etc. Otorga gran valor al conocimiento de la psicología del enemigo.La falta de ideales es tan importante como la ausencia de suministros.Intenta concienciar a sus jefes en lo interesante que es conocer la psicología del enemigo, respetar sus creencias religiosas, urbanizar el territorio para mejorar el bienestar del pueblo, y dignificar la situación marginal de la mujer musulmana.La guerra responde a un plan premeditado del Estado Mayor que debe conocer de antemano la psicología del enemigo, la naturaleza del terreno, la maniobrabilidad de sus tropas y las posibilidades del éxito.

4. El Nacionalismo marroquí es a su juicio una ideología importada de Europa, que ha triunfado en Turquia.Son las elites de la sociedad marroqui que estudian en las Universidades europeas, las primeras en defender la libertad y lucha contra el invasor.Examina el apoyo más moral que económico de los Soviets, defensores de la descolonización, y la ayuda material interesada de las industrias de guerra europeas; que fomentan la rebeldía para aumentar los beneficios de sus empresas ysus fortunas particulares.No obstante, lo ve todavia como un fenómeno tardio, que se consolidará en un futuro, como en realidad sucedio. Antes era preciso que Francia y España civilizaran el tribal espacio marroquí. 